\title{
CONTROLE SOCIAL NO SISTEMA ESTADUAL DE INCENTIVOS A SERVIÇOS AMBIENTAIS DO ACRE: RELATO DA EXPERIÊNCIA DE IMPLANTAÇÃO E FUNCIONAMENTO DO COMITÊ LOCAL DE PADRÕES
}

\author{
SOCIAL CONTROL IN THE STATE SYSTEM OF INCENTIVES \\ FOR ENVIRONMENTAL SERVICES IN ACRE: REPORT \\ ABOUT THE EXPERIENCE OF IMPLEMENTATION AND \\ OPERATION OF THE LOCAL STANDARDS COMMITTEE
}

\author{
Ayri Saraiva Rando \\ SOS Amazônia - AC - Brasil \\ Marta Nogueira de Azevedo \\ Instituto de Mudanças Climáticas e Regulação de Serviços Ambientais do Acre - AC - \\ Brasil
}

\begin{abstract}
Resumo: O controle social, a participação e a transparência são aspectos relevantes nas políticas de incentivos e pagamentos por serviços ambientais. A Comissão Estadual de Validação e Acompanhamento - CEVA é o colegiado responsável por garantir a transparência e exercer o controle social do Sistema de Incentivos a Serviços Ambientais do Acre - SISA. Este artigo aborda a dificuldade em garantir tal transparência em relação às etapas previstas na implantação dos padrões sociais e ambientais de Redução das Emissões por Desmatamento e Degradação Florestal - REDD+, portanto, o mesmo visa acompanhar o nível de transparência dessa comissão a partir da comparação das publicações previstas no documento de diretrizes da Iniciativa Internacional para implantação dos padrões mencionados com as publicações realizadas. Os métodos utilizados são a pesquisa bibliográfica e o levantamento documental. Em relação aos resultados esperados, o artigo em questão proporciona um esforço complementar ao projeto de institucionalização dos padrões mencionados no SISA, no que tange à publicação e à transparência no processo de implantação das salvaguardas neste Estado.
\end{abstract}

Palavras-chave: SISA. CEVA. Controle Social.

\begin{abstract}
The social control, the participation and the transparency are important aspects in the policies of incentives and payment for environmental services. The State Commission for Validation and Monitoring - CEVA is the college responsible for ensuring transparency and exert the social control of the State System of Incentives for Environmental Services in Acre - SISA. This article discusses the difficulty in ensuring the transparency in relation to the provided steps in the implementation of social and environmental standards for REDD +, therefore, it is intended to monitor the level of transparency of this commission from the comparison of the provided publications in the guidance document of the International Initiative for the implementation of the mentioned standards with the made publications. The methods used are literature review and documentary survey. Against expected results, the article in question provides a complementary effort to the project of institutionalization of social and environmental standards for REDD + in SISA, with respect to the publication and transparency in the implementation process of the safeguards in this state.
\end{abstract}

Keywords: SISA. CEVA. Social Control. 


\section{Introdução}

A partir dos anos 1990, com a Constituição Federal de 1988, a sociedade civil passa a participar do desenho e da implementação das políticas públicas por meio da criação e do funcionamento de conselhos participativos. Desde então, a participação da sociedade no acompanhamento da realização das despesas públicas é essencial para o bom gerenciamento dos recursos.

A consolidação da democracia eleva a importância do controle e da avaliação do impacto de políticas públicas, sendo que este controle significa verificar se a realização das atividades governamentais atende à finalidade pública, à legislação e aos princípios básicos aplicáveis ao setor público. Quando esse controle inclui a participação dos cidadãos e da sociedade organizada no controle do gasto público, a partir da avaliação e do monitoramento das atividades mencionadas e a partir da exigência do uso adequado dos recursos públicos, aborda-se, então, o controle social de políticas públicas.

O número crescente de iniciativas de Compensações por Serviços Ambientais - CSA e de Pagamentos por Serviços Ambientais - PSA demonstra a relevância destas mesmas em busca de sanar parte dos problemas oriundos da poluição ambiental e da degradação dos serviços ecossistêmicos disponíveis, e em busca de promover e aprimorar o uso de instrumentos econômicos na gestão ambiental e na política ambiental, como oportunidade de fomentar a política ambiental mista de comando e controle.

No Acre, a Lei $\mathrm{N}^{\circ} 2.308$, de 22 de outubro de 2010, cria o SISA, o Programa de Incentivos por Serviços Ambientais - ISA Carbono e demais Programas de Serviços Ambientais e Produtos Ecossistêmicos do Estado do Acre. Essa política pública possibilita a implantação do mecanismo de REDD+, que é um exemplo de mecanismo de compensações por serviços ambientais, relativo à absorção, ao fluxo e ao estoque de carbono.

Conforme GTA et al. (2010), os mecanismos de REDD+ possuem riscos e oportunidades, destacando-se entre os riscos, a falta de garantias da participação de diversos atores da sociedade na construção, implementação e avaliação de políticas e projetos de REDD+.

As salvaguardas sociais e ambientais de REDD+ têm como função eliminar os riscos e potencializar as oportunidades deste tipo de mecanismo. Os padrões sociais e ambientais de REDD+ da Iniciativa Internacional (REDD+ SES), iniciativa esta, secretariada pela Aliança para o Clima, Comunidade e Biodiversidade - CCBA (sigla em inglês) e pela Care Internacional, são as salvaguardas do SISA, em implementação no Acre.

Com a finalidade de reduzir ou eliminar o risco da baixa participação, o processo referente ao controle social ganha notoriedade e é fundamental. A CEVA é o colegiado responsável por garantir a transparência e exercer o controle social de tal política pública.

A problemática deste artigo é a dificuldade em garantir a transparência relativa às ações e atividades dessa comissão, como comitê local de padrões, fora 
do ambiente de discussões e decisões dos conselhos estaduais do Acre, devido à pequena quantidade de publicações sobre o tema.

O objetivo geral do mesmo é acompanhar o nível de transparência de tal colegiado a partir da comparação das publicações previstas no documento de diretrizes da Iniciativa Internacional para implantação dos REDD+ SES com as publicações realizadas, socializando ao público uma sistematização da experiência da CEVA no exercício de comitê local desses padrões, em ambiente que extrapola o ambiente dos conselhos acrianos e em situação que envolveu o coletivo desses conselhos. Já os objetivos específicos são: promover a transparência e o acesso às informações; identificar aprendizagens que sirvam de modelo e referência para outros programas; apontar desafios e registrar recomendações à CEVA para uma boa continuidade na função deste comitê.

\section{Metodologia}

Este artigo utiliza-se da pesquisa bibliográfica e do levantamento documental referente às diretrizes da Iniciativa Internacional para implementação dos padrões em questão, aos relatórios, às apresentações realizadas em eventos, aos resultados de consultas públicas, às memórias das atividades executadas pelo projeto de testes dos padrões sociais e ambientais de REDD+ junto ao Programa ISA Carbono e pelo projeto de institucionalização dos padrões sociais e ambientais de REDD+ no SISA, executados em parceria com o Instituto de Mudanças Climáticas e Regulação de Serviços Ambientais do Acre - IMC com a ONG CARE Brasil.

Para acompanhar a transparência no processo de implantação desses padrões no Acre, compara-se as publicações previstas nas diretrizes citadas com as publicações concretizadas até o momento.

O período considerado neste artigo é do dia 18 de outubro de 2011, dia da eleição e seleção dos membros da sociedade civil organizada para atuação na CEVA, ao dia 30 de junho de 2013, data de encerramento do projeto de institucionalização dos padrões sociais e ambientais de REDD+ no SISA.

\section{Organização do Estado Democrático de Direito no Brasil}

A consolidação da democracia representativa no Brasil vem se fortalecendo progressivamente desde a reabertura política pós-ditadura, destacando-se como marcos de tal processo os anos de 1974, pela eleição de senadores e deputados federais de oposição ao regime militar, e de 1989, quando assumiu o primeiro presidente eleito democraticamente. Outro grande marco a ser destacado é o amplo debate público em torno da Constituição Federal de 1988, o qual possibilitou a aglutinação das forças da sociedade civil de oposição ao autoritarismo, permitiu a elaboração de uma Constituição em que predominava o espírito participativo e introduziu diversos mecanismos de participação social direta para democratização do Estado (CYMBALISTA et al., 2008). 
Cymbalista et al. (2008) enfatizam que, a partir dos anos 1990, a sociedade civil tem atuado pela concretização dos princípios estabelecidos pela Constituição, participando da concepção e implantação de uma variedade de novas políticas públicas, sendo estes princípios: a criação de conselhos gestores com participação direta da população, a consolidação dos sistemas de políticas públicas e a aprovação de legislação específica para as diferentes áreas das políticas sociais.

No Brasil, a forma de governo é republicana, o sistema de governo é presidencialista e a forma do Estado é federativa. Como país republicano, o Estado brasileiro deve priorizar os direitos fundamentais, não deve admitir que o interesse privado se sobreponha ao interesse público, deve fundar-se na ética e na divisão e equilíbrio entre os poderes. Já, como presidencialista, é dirigido por um Presidente da República, chefe do poder Executivo, eleito para mandato de quatro anos, a ser exercido com o auxílio de Ministros de Estado. Como federativo, o Estado em questão é formado por quatro componentes autônomos - a União, os Estados, o Distrito Federal e os Municípios (CGU, 2010).

Também de acordo com a Controladoria Geral da União (2010), o Estado precisa do ingresso de recursos públicos para que seus órgãos e agentes potencializem sua missão constitucional de construir uma vida justa e livre para todo o povo, que deve ser a origem e o fim de toda a atividade estatal. Tais recursos são as receitas, que podem ser originárias e derivadas. As receitas originárias são obtidas do patrimônio do próprio Estado, via venda de bens e serviços e as derivadas são do patrimônio privado, por meio das reparações de guerra, das penalidades e dos tributos.

Enfim, para a Controladoria Geral da União (2010), o funcionamento do Estado demanda uma arrecadação de receitas, as quais, na medida em que possibilitam a realização de programas, projetos e ações do Estado, transformamse em despesas. Para que esse processo se aproxime do adequado, é preciso participação da sociedade no planejamento prévio, na gestão e no acompanhamento das políticas públicas, ou seja, a sociedade deve exercer o controle dos recursos públicos utilizados nas realizações dos fins do Estado.

Portanto, a participação da sociedade no acompanhamento da realização das despesas públicas é essencial para o bom gerenciamento dos recursos.

\subsection{Controle Social e Transparência}

A consolidação da democracia reforça o controle e a avaliação do impacto de políticas públicas, que demandam das ONGs e dos movimentos sociais um conhecimento qualificado e detalhado do processo de construção e monitoramento destas políticas (CYMBALISTA et al., 2008).

Segundo a Controladoria Geral da União (2010), na administração pública, o ato de controlar tem o significado de verificar se a realização de uma determinada atividade governamental atendeu à finalidade pública, à legislação e aos princípios básicos aplicáveis ao setor público. O controle institucional é a forma 
de controle exercida pela própria administração pública e por organizações privadas.

O controle da administração pública não se restringe ao controle institucional mencionado, sendo fundamental à coletividade que haja a participação dos cidadãos e da sociedade organizada no controle do gasto público, avaliando e monitorando continuamente as ações governamentais, além da exigência do uso adequado dos recursos públicos. A participação e a exigência citadas são denominadas controle social (CGU, 2010).

Assim, a Controladoria Geral da União (2010, p. 16) define controle social como "a participação do cidadão na gestão pública, na fiscalização, no monitoramento e no controle das ações da Administração Pública. Trata-se de importante mecanismo de prevenção da corrupção e de fortalecimento da cidadania".

Outra definição possível para controle social é, de acordo com Serafim (2007), uma forma específica de participação da sociedade em relação direta com - Estado, na qual a política pública deve ser abordada desde a sua definição, passando por sua execução e metas a serem atingidas, até a avaliação de seu bom funcionamento, visando o cumprimento do interesse público. Esse processo pode se realizar em espaços públicos de discussão, instâncias formais de participação e por meio de mecanismos que possibilitem a troca de informações e debates mais profundos entre uma pluralidade de atores da sociedade e do Estado.

O controle social pode ser exercido de maneira restrita quando envolve a atividade de acompanhamento da execução das políticas e do orçamento, incluindo a averiguação da legalidade das ações e, em caso de descumprimento legal, a punição dos gestores responsáveis, ou pode ser exercido de forma ampliada quando visa garantir os interesses coletivos por meio da participação social na definição e no desenvolvimento das políticas públicas, além do acompanhamento da execução das ações e do orçamento (SERAFIM, 2007).

Ainda conforme Serafim (2007), a perspectiva de controle social ampliado é resultado da atuação autônoma e qualificada das organizações da sociedade civil, indo além da averiguação da legalidade das ações do Executivo, constituindo, assim, um processo de construção coletiva de projetos de sociedade e de propostas de políticas públicas. Portanto, o controle social está vinculado diretamente com a participação, sendo que a confirmação da perspectiva de controle social ampliado engloba as seguintes linhas de atuação e análise: transparência e acesso à informação sobre as políticas e ações públicas; monitoramento e possibilidade de acompanhamento sistemático da execução de ações; e participação social na definição e no desenvolvimento das mesmas.

A participação ativa do cidadão no controle social pressupõe a transparência das ações governamentais por meio da possibilidade, propiciada pelo governo, do cidadão entender os mecanismos de gestão para poder influenciar na tomada de decisões. Conclui-se, então, que o acesso do cidadão à informação simples e compreensível é o ponto de partida para uma maior transparência (CGU, 2010). 
Para a Controladoria Geral da União (2010), a transparência da gestão pública e das ações governamentais depende de diversas ações, tais como: publicação de informações; existência de espaços para a participação popular na gestão pública; construção de canais de comunicação e de diálogo entre sociedade civil e governantes; funcionamento dos Conselhos, órgãos coletivos do poder público e da sociedade civil com o papel de participar da elaboração, execução e fiscalização das políticas públicas; modernização dos processos administrativos; simplificação da estrutura de apresentação do orçamento público, aumentando, assim, a transparência do processo orçamentário.

Assim, nota-se que a efetivação adequada do controle social é influenciada diretamente pelo acesso às informações públicas por parte dos cidadãos, sendo que esta transparência deriva da ação simultânea do governo e da sociedade, com o governo levando informações à sociedade e esta última buscando tais informações (CGU, 2010).

\subsection{Controle Social de Programas e Políticas de Compensaçôes e Pagamentos por Serviços Ambientais}

Born e Talocchi (2002) definem serviços ambientais como a capacidade da natureza em continuar reproduzindo e mantendo as condições ambientais originais.

Guedes e Seehusen (2011) consideram que os serviços ambientais englobam os serviços proporcionados ao ser humano tanto por ecossistemas naturais quanto pelos serviços providos por ecossistemas manejados diretamente pelo homem.

Praticamente todos os mecanismos de CSA e/ou de PSA existentes compreendem serviços ambientais associados a uma das quatro categorias distintas representadas pela retenção ou captação de carbono; conservação da biodiversidade; conservação de serviços hídricos e conservação de beleza cênica (WUNDER et al., 2008).

Os instrumentos de CSA podem ser conceituados como sendo a transferência de recursos ou benefícios da parte que se beneficia com a provisão destes serviços para a parte que ajuda a prover e manter os serviços em questão, sendo o princípio orientador de tal relação o chamado princípio do protetorrecebedor (BORN; TALOCCHI, 2002).

Segundo Wunder et al. (2008), PSA é uma transação voluntária, na qual um serviço ambiental bem definido ou um uso da terra que possa assegurar este serviço é comprado por, pelo menos, um comprador, de, pelo menos, um provedor sob a condição de que o provedor garanta a provisão deste serviço.

No Acre, a Lei Estadual N 2.308, de 22 de outubro de 2010, cria o SISA, o Programa de Incentivos a Serviços Ambientais Carbono do Acre - Programa ISA Carbono e demais Programas de Serviços Ambientais e Produtos Ecossistêmicos do Estado do Acre. 
O SISA inclui princípios e possui uma arquitetura institucional que possibilita ao estado criar elos com mercados emergentes de serviços ambientais (IPAM, 2012).

O diferencial do Estado do Acre é a sua jurisdição aprovada, pertinente ao SISA, a qual aborda um sistema geral que engloba vários tipos e diversas classes de serviços ambientais, sendo o Programa ISA Carbono, que inclui a possibilidade de projetos e planos de REDD+, o que se encontra em estágio mais avançado. Outro diferencial do Programa ISA Carbono e do SISA é o processo de implementação das salvaguardas sociais e ambientais de REDD+.

De acordo com Parker et al. (2009), a ideia básica da REDD é simples: os países que estão dispostos e em condições de reduzir as emissões por desmatamento deveriam ser recompensados financeiramente por fazê-lo. As abordagens anteriores para conter o desmatamento global, até agora, não tiveram sucesso e mecanismos de REDD podem oferecer um novo marco referencial para permitir que os países com altos índices de desmatamento rompam esta tendência histórica.

Cenamo et al. (2010) comentam que o mecanismo, inicialmente chamado de RED, passou por processos de construção e inclusão de outras atividades em seu escopo. Em 2005, quando o mecanismo foi proposto, incluía apenas desmatamento (RED), e conforme a inclusão de outras atividades, a sigla foi se modificando e chegou a ser REDD+, que significa Redução de Emissões do Desmatamento e Degradação Florestal, o papel da conservação, o manejo florestal sustentável, o reflorestamento e o aumento dos estoques de carbono.

Conforme GTA et al. (2010), os mecanismos de REDD+ possuem riscos e oportunidades, destacando-se, entre os riscos de REDD+, a falta de garantias da participação de diversos atores da sociedade na construção, implementação e avaliação de políticas e projetos de REDD+, além da perspectiva de compensar apenas aqueles que historicamente são responsáveis pelo desmatamento e não aqueles que vêm conservando as florestas historicamente.

Entretanto, em relação às oportunidades, destacam-se: frear o desmatamento e diminuir as emissões de Gases de Efeito Estufa - GEE a ele associadas; combater o aquecimento global e a um menor custo; promover incentivos à conservação da biodiversidade; garantir a proteção aos direitos dos Povos Indígenas e Comunidades Tradicionais que vivem nessas florestas e delas dependam para sobreviver; melhorar as condições socioeconômicas dos Povos Indígenas e Comunidades Tradicionais, valorizando seu papel de agentes históricos que tem significativamente contribuído para a conservação da floresta em pé (GTA et al., 2010).

Tais riscos e oportunidades podem ser considerados para mecanismos de compensações e pagamentos por serviços ambientais como o SISA, portanto, as salvaguardas sociais e ambientais de REDD+ surgem justamente para minimizar os riscos e potencializar as oportunidades desse tipo de mecanismo, salvaguardando aspectos socioambientais, tais como a garantia do direito dos povos indígenas, populações tradicionais e comunidades locais; a participação dos mesmos no desenho, implantação e avaliação; o consentimento livre, prévio e informado 
desses atores; os critérios para a repartição justa e equitativa de benefícios; a transparência nos processos; e outros.

No SISA, a implementação das suas salvaguardas corresponde à implantação dos Padrões Sociais e Ambientais de REDD+ da Iniciativa Internacional (REDD+ SES, na sigla em inglês).

\subsection{Comissão Estadual de Validação e Acompanhamento do Sistema de Incentivos a Serviços Ambientais do Acre}

De acordo com a lei de criação do SISA, a CEVA, o IMC, o Comitê Científico e a Ouvidoria são os instrumentos de participação, gestão, controle e registro do SISA e integram o arranjo institucional dessa política pública. Esse arranjo também é composto pela Companhia de Desenvolvimento de Serviços Ambientais - COSA como instrumento de execução. Os instrumentos de planejamento correspondem aos planos de ação e aos projetos a eles associados, aos subprogramas e aos programas, e aos projetos especiais da iniciativa privada.

Na sequência, a Figura 1 mostra o esquema de funcionamento do SISA.

Figura 1. Funcionamento do SISA

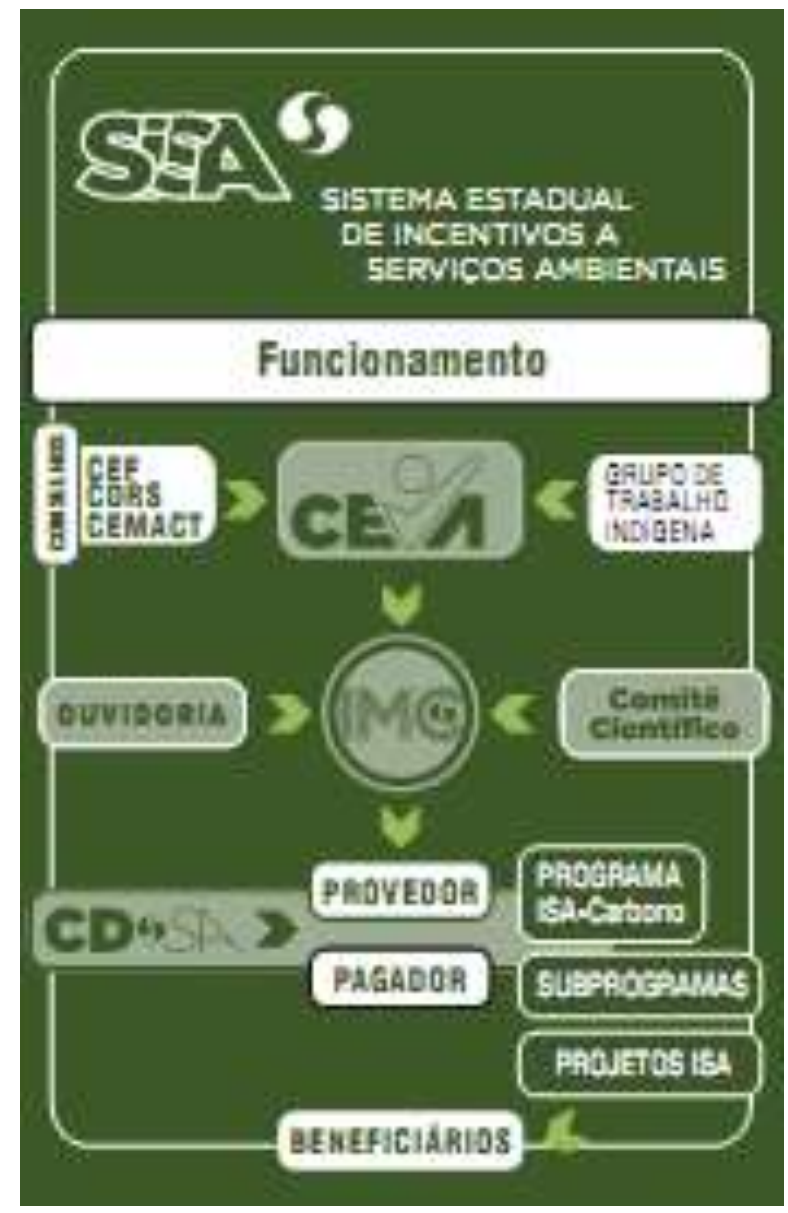

Fonte: CEVA et al. (2013). 
A CEVA é uma estrutura vinculada ao IMC, composta por oito instituições, quatro representantes do Poder Público e quatro da sociedade civil organizada, frisando que o número de membros pode ser ampliado por meio de decisão do coletivo formado pelo Conselho Estadual de Meio Ambiente, Ciência e Tecnologia - CEMACT, pelo Conselho de Florestas - CFE e pelo Conselho de Desenvolvimento Rural Sustentável - CEDRFS, mantendo obrigatoriamente a paridade entre o Poder Público e a sociedade civil (CEVA et al., 2013).

Entre as atribuições da CEVA previstas na Lei Estadual № 2.308, ressalta-se a atribuição de garantir a transparência e o controle social dos programas, subprogramas, planos de ação e projetos especiais do SISA; e de elaborar e apresentar relatórios anuais de suas atividades ao coletivo dos Conselhos. Já, conforme CEVA et al. (2013), outra atribuição destacada é o exercício do papel de Comitê Local dos Padrões Sociais e Ambientais de REDD+ da Iniciativa Internacional, que inclui atividades como: participação no aperfeiçoamento permanente desses padrões; contribuição na comparação e relação de tais padrões com outros padrões e salvaguardas socioambientais existentes; análise e validação do processo de monitoramento, relatoria e verificação - MRV, em relação aos princípios e critérios estabelecidos; e apreciação e aprovação dos indicadores acrianos a serem utilizados na avaliação do cumprimento dos princípios e critérios mencionados.

Tratando-se da participação direta no processo de controle social do SISA, observa-se que, para compor a CEVA, como representante da sociedade civil organizada, é necessário atender aos procedimentos e critérios estabelecidos pelo Decreto $\mathrm{N}^{\circ}$ 2.002, de 31 de maio de 2011. Para participação como representante do Poder Público, os candidatos deverão ser nomeados por seleção do governador do Estado do Acre (CEVA et al., 2013).

A estrutura de funcionamento da comissão em questão está definida no seu regimento interno. Existe uma instituição coordenadora e outra que exerce a função de Secretaria Executiva, sendo que o exercício da coordenação é alternado entre as instituições governamentais e não governamentais. Os grupos técnicos de trabalho - GTs são temporários, sendo que o primeiro GT a integrar oficialmente a CEVA foi o GT Indígena, desde 16/10/2012, conforme Resolução № 10.907 (CEVA et al., 2013).

A Figura 2 abaixo apresenta a estrutura de funcionamento da comissão com os componentes da mesma. 
Figura 2. Estrutura de funcionamento da CEVA

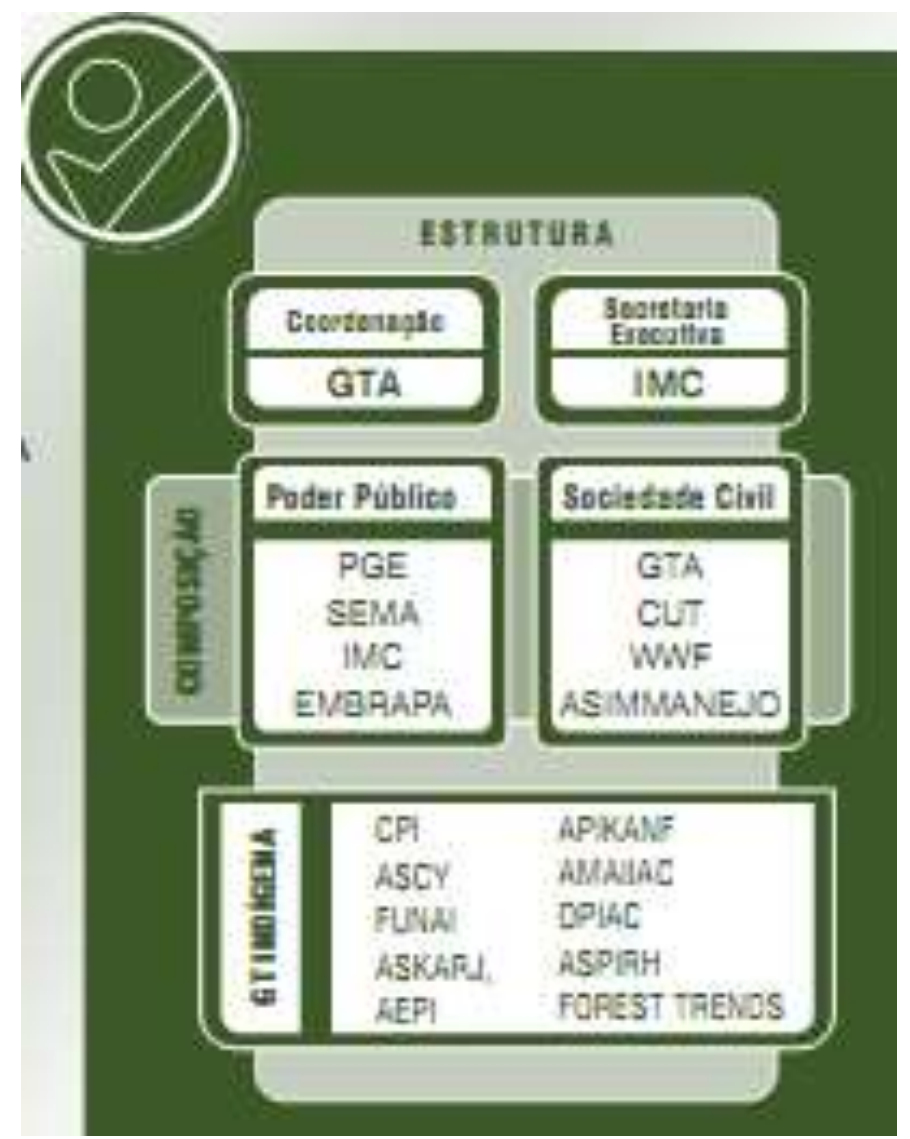

Fonte: CEVA et al. (2013).

3.4 Salvaguardas Socioambientais do Sistema de Incentivos a Serviços Ambientais do Acre

De acordo com Bonfante et al. (2010), na Conferência das Partes - COP-15 em Copenhagen, em dezembro de 2009, começaram as discussões sobre salvaguardas socioambientais de REDD+. O texto produzido nessa conferência enfatizou a importância de envolvimento de múltiplos atores da sociedade civil na discussão sobre REDD+, destacando que este tema não pode ficar restrito às discussões internacionais, mas precisa ser levado para uma discussão nacional ou subnacional, envolvendo governos, setor privado, sociedade civil e, em especial, povos indígenas e comunidades tradicionais.

Bonfante et al. (2010) destacam que as salvaguardas socioambientais brasileiras de REDD + foram organizadas em princípios e critérios para facilitar a discussão em temáticas específicas e relevantes para REDD+.

Um padrão voluntário internacional para salvaguardas socioambientais de REDD + também está em desenvolvimento por meio de um processo envolvendo diversos atores, o qual é secretariado pela CCBA, e pela ONG CARE Internacional. Tal padrão é denominado Padrões Sociais e Ambientais de REDD+ da Iniciativa Internacional (REDD + Social and Environmental Standard - REDD + SES, na sigla em inglês), o qual pretende e deve ser utilizado por políticas e programas governamentais nos seus diferentes níveis (MOSS; NUSSBAUM, 2011). 
A iniciativa CCBA e CARE reconhece a crescente consciência a respeito da necessidade de salvaguardas socioambientais efetivas, procurando definir e consolidar o apoio para um nível mais elevado de desempenho social e ambiental do Programa ISA Carbono do Acre.

No Acre, as salvaguardas em implantação no programa citado e no SISA equivalem aos REDD+ SES. É relevante ressaltar a relação entre salvaguardas socioambientais e os padrões sociais e ambientais da Iniciativa Internacional, sendo as salvaguardas equivalentes às diretrizes gerais ou à definição de critérios mínimos a serem identificados, respeitados e reconhecidos em relação a aspectos sociais e ambientais relevantes em iniciativas de REDD+ e/ou em iniciativas de CSA. Já os padrões vão além da definição de critérios mínimos ao chegar na definição de indicadores e da estratégia de Monitoramento, Relatoria e Verificação - MRV, sendo assim, uma ferramenta de avaliação, demonstração e comunicação do desempenho social e ambiental de programas e políticas públicas (RANDO, 2013).

Segundo REDD+ SES (2010):

os padrões sociais e ambientais em questão integram um conjunto de princípios, critérios e indicadores $(\mathrm{PCl})$ e processo de monitoramento, relatoria e verificação (MRV). Estes padrões são uma ferramenta para avaliar, demonstrar e comunicar um processo transparente, inclusivo e equitativo; os benefícios sociais e ambientais; e o respeito aos direitos dos Povos Indígenas e das comunidades locais.

Para REDD + SES (2010), nos níveis de princípios e critérios, os padrões são genéricos, ou seja, os mesmos em todos os países. No nível de indicador e da estratégia de $M R V$, há um processo para interpretação específica para países a fim de desenvolver um conjunto de indicadores adaptados para o contexto particular dos países. Os objetivos da implementação de tais padrões são: ajudar os governos a desenvolver apoio nacional e internacionalmente para seus programas, possibilitando, por exemplo, acesso preferencial a recursos; estimular a melhoria do desempenho social e ambiental de REDD+ e outros programas de carbono florestal em países e estados; desenvolver maior apoio global para uma ação efetiva e equitativa.

A primeira versão dos PSAs de REDD+ é de primeiro de junho de 2010, engloba 8 princípios e 34 critérios, além de propor 98 indicadores (REDD+ SES, 2010).

Já a segunda versão dos Padrões Sociais e Ambientais de REDD+ é de 10 de setembro de 2012, engloba 7 princípios e 28 critérios, e propõe 64 indicadores (REDD+ SES, 2012).

Ressalta-se que o princípio 6 dessa última versão é pertinente à participação plena e eficaz dos titulares de direitos e atores relevantes em Programas de REDD+. Tal participação está diretamente relacionada com o acesso às informações sobre REDD+, que, por sua vez, pode ser facilitado com a disponibilização e a publicação técnica e/ou científica de artigos, que divulgam e disponibilizam informações a respeito do processo de implementação desses 
padrões, no que tange às ações e atividades desenvolvidas pelo Comitê Local de Padrões, que no caso acriano, é a CEVA.

Observa-se que, baseando-se nas experiências dos países pilotos na implementação desses padrões, ou seja, com as lições aprendidas e recomendações feitas pelas equipes de cinco territórios (Acre-Brasil, Equador, Indonésia, Nepal e Tanzânia), que começaram a testar os padrões mencionados, foi elaborado, pela Iniciativa Internacional, um guia para implementação destes padrões nos países, estados ou províncias, o qual define tal implementação em dez etapas.

Conforme REDD+ SES (2012), essas etapas são:

1a) Reuniões e oficinas para conscientização e capacitação;

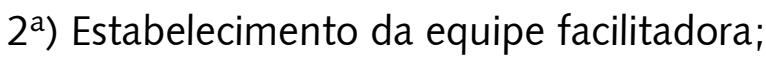

$\left.3^{a}\right)$ Criação do Comitê Local de Padrões;

$4^{\text {a) }}$ Desenvolvimento de um plano para o processo todo;

$\left.5^{a}\right)$ Desenvolvimento das minutas dos indicadores específicos para países;

6а) Organização de consultas sobre tais indicadores;

$7^{a}$ ) Construção de um plano de monitoramento desses indicadores;

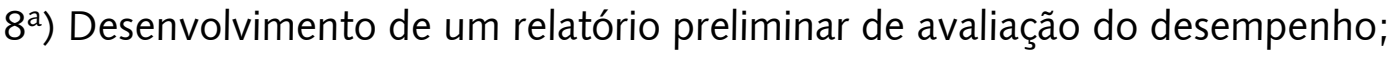

9a) Organização da revisão do relatório preliminar de avaliação do desempenho pelos atores;

10ª) Publicação do relatório de avaliação do desempenho.

É relevante destacar que a criação do Comitê Local de Padrões está prevista na terceira etapa de implementação dos REDD+ SES no âmbito local (nacional ou subnacional) e que o comitê em questão possui atribuições específicas nesse processo de implementação, as quais poderão ser visualizadas no próximo item.

\subsection{Comitê Local dos Padrões Sociais e Ambientais no Acre}

Primeiramente, enfatiza-se a governança referente ao desenvolvimento dos REDD+ SES, que envolveu processo participativo e inclusivo, em que o Comitê Internacional de Padrões supervisiona o desenvolvimento desses padrões, aprova cada versão dos padrões e é composto por governos que se encontram em fase de desenho e em fase de implantação de programas e políticas de REDD+, governos de países desenvolvidos, organizações de povos indígenas, associações comunitárias, ONGs sociais e ambientais e setor privado, visando a garantia de equilíbrio na participação dos atores e promovendo maior participação de atores do hemisfério Sul. Enfatiza-se também, que a CCBA e a CARE Internacional são organizações facilitadoras ou que atuam como Secretariado dessa Iniciativa Internacional. 
Como o arranjo institucional do SISA criou a CEVA e o coletivo dos três conselhos estaduais dentro dos seus instrumentos de participação e delegou a atribuição de garantir a transparência e o controle social da política pública em questão à CEVA, ela própria assume a atribuição específica de exercer a função de Comitê Local de Padrões no Acre.

Na prática, essa comissão iniciou o seu funcionamento após escolha dos seus membros representantes da sociedade civil organizada em eleição ocorrida durante reunião do coletivo de conselhos, realizada no dia 18 de outubro de 2011.

As ações e atividades da CEVA, cumprindo essa atribuição específica, foram aplicadas no âmbito de dois projetos. O primeiro deles foi o projeto de testes dos padrões sociais e ambientais de REDD+ junto ao Programa ISA Carbono, o qual foi executado no período de julho de 2010 até fevereiro de 2012, sendo a equipe de facilitação de tal projeto composta inicialmente pela Secretaria de Estado de Meio Ambiente do Acre - SEMA e pela CARE Brasil e, posteriormente, pelo IMC e pela CARE Brasil.

O segundo projeto foi denominado Institucionalização dos padrões sociais e ambientais de REDD + no SISA, o qual foi executado no período de março de 2012 até junho de 2013, sendo que a equipe de facilitação continuou a cargo do IMC e da CARE Brasil.

O Quadro 1 seguinte mostra as ações e atividades da CEVA como Comitê Local de Padrões, por etapa de implementação dos padrões da Iniciativa Internacional.

Quadro 1. Ações e atividades da CEVA como Comitê Local de Padrões, por etapa de implementação dos REDD+ SES

\begin{tabular}{|c|c|}
\hline Etapa & Ações e Atividades \\
\hline $\begin{array}{l}\text { 1. Reuniões e oficinas para } \\
\text { conscientização e capacitação }\end{array}$ & $\begin{array}{l}\text { - Reuniões setoriais preparatórias para o processo eleitoral da CEVA e para } \\
\text { participação da mesma na consulta pública dos indicadores acrianos; } \\
\text { - Oficinas de consulta pública desses indicadores; } \\
\text { - Oficinas de revisão e validação desses indicadores e do seu plano de } \\
\text { monitoramento; } \\
\text { - Oficinas de planejamento estratégico do Departamento de Monitoramento do } \\
\text { IMC e de planejamento operacional da CEVA; } \\
\text { - Reuniões ordinárias e extraordinárias. }\end{array}$ \\
\hline $\begin{array}{l}\text { 2. Estabelecimento da equipe } \\
\text { de facilitação }\end{array}$ & - Não houve participação da CEVA nessa etapa. \\
\hline $\begin{array}{l}\text { 3. Criação do Comitê Local de } \\
\text { Padrões (CEVA) }\end{array}$ & - Reuniões setoriais preparatórias para o processo eleitoral da CEVA. \\
\hline $\begin{array}{l}\text { 4. Desenvolvimento do } \\
\text { Plano de Trabalho para } \\
\text { implantação dos padrões }\end{array}$ & $\begin{array}{l}\text { - Após processo eleitoral e composição da CEVA, a equipe de facilitação manteve } \\
\text { comunicação contínua junto à Secretaria Executiva (IMC) e à Coordenação da } \\
\text { CEVA (GTA) para o planejamento e desenvolvimento das atividades deste } \\
\text { colegiado como Comitê Local de Padrões. }\end{array}$ \\
\hline $\begin{array}{l}5 . \quad \text { Desenvolvimento da } \\
\text { minuta dos indicadores para o } \\
\text { Acre }\end{array}$ & $\begin{array}{l}\text { - Oficinas e reuniões setoriais preparatórias ao processo de consulta pública } \\
\text { referente à minuta dos indicadores acrianos, antes da composição da CEVA; } \\
\text { - Oficinas e reuniões de discussão, revisão e validação dos indicadores acrianos, } \\
\text { após composição da CEVA. }\end{array}$ \\
\hline
\end{tabular}


Continuação

\begin{tabular}{|l|l|}
\hline $\begin{array}{l}\text { 6. Organização de } \\
\begin{array}{l}\text { Consulta sobre a minuta dos } \\
\text { indicadores acrianos }\end{array}\end{array}$ & $\begin{array}{l}\text { - A CEVA não organizou a consulta, mas participou da consulta em si, por } \\
\text { meio de recomendações e contribuições feitas durante as oficinas e as } \\
\text { reuniões setoriais preparatórias. }\end{array}$ \\
\hline $\begin{array}{l}\text { 7. Preparação rano de monitoramento do } \\
\text { Plano }\end{array}$ & $\begin{array}{l}\text { - Oficinas e reuniões de discussão, revisão e validação dos indicadores } \\
\text { acrianos e do seu plano de monitoramento. }\end{array}$ \\
\hline $\begin{array}{l}\text { 8. Desenvolvimento } \\
\text { do relatório preliminar de } \\
\text { avaliação do desempenho }\end{array}$ & - Etapa ainda não realizada. \\
\hline $\begin{array}{l}\text { 9. Organização de } \\
\text { consulta pertinente ao }\end{array}$ & \\
$\begin{array}{l}\text { relatório preliminar de de } \\
\text { avaliação do desempenho } \\
\text { para revisão }\end{array}$ & - Etapa ainda não realizada. \\
\hline $\begin{array}{l}\text { 10. Publicação } \\
\text { relatório de avaliação do do } \\
\text { desempenho }\end{array}$ & - Etapa ainda não realizada. \\
\hline
\end{tabular}

Fonte: CARE Brasil e IMC (2013). cronológica.

O Quadro 2 abaixo apresenta as atividades específicas da CEVA de forma

Quadro 2. Atividades específicas da CEVA como Comitê Local de Padrões, de forma cronológica, por semestre

\begin{tabular}{|c|c|}
\hline Período & Atividades \\
\hline $\begin{array}{c}1^{\circ} \text { Semestre de } \\
2011\end{array}$ & - Reuniões preparatórias ao processo eleitoral da CEVA. \\
\hline $\begin{array}{l}2^{\circ} \text { Semestre de } \\
2011\end{array}$ & $\begin{array}{l}\text { - } 1 \text { oficina com produtores rurais e extrativistas, referente ao processo de consulta pública } \\
\text { dos indicadores; } \\
-1 \text { oficina com lideranças indígenas, referente ao processo de consulta pública dos } \\
\text { indicadores; } \\
\text { - } 2 \text { reuniões setoriais preparatórias referentes ao processo de consulta pública dos } \\
\text { indicadores; } \\
\text { - Workshop de intercâmbio e aprendizagem no Acre; } \\
\text { - Reunião do coletivo dos conselhos para eleição dos membros da sociedade civil da CEVA. }\end{array}$ \\
\hline $\begin{array}{c}1^{\circ} \text { Semestre de } \\
2012\end{array}$ & $\begin{array}{l}\text { - Oficina de discussão e aprovação da } 2^{a} \text { proposta preliminar dos indicadores acrianos; } \\
\text { - } 2 \text { workshops sobre Gênero e REDD+, pertencente à pesquisa-ação nesse tema; } \\
\text { - Workshop de planejamento estratégico do Departamento de Monitoramento do IMC; } \\
\text { - Reunião com o coletivo dos conselhos para apresentação dos indicadores acrianos; } \\
\text { - Reunião para nova apreciação e recomendações aos indicadores acrianos, seus } \\
\text { verificadores e fontes de verificação. }\end{array}$ \\
\hline $\begin{array}{l}2^{\circ} \text { Semestre de } \\
2012\end{array}$ & $\begin{array}{l}\text { - Workshop de Planejamento Operacional da CEVA; } \\
\text { - Reunião para apreciação e recomendações relativas à verificação do cumprimento dos } \\
\text { padrões no Projeto Purus; } \\
\text { - Reunião de alinhamento durante visita da Iniciativa Internacional ao Acre, a qual estava } \\
\text { representada pela CCBA; } \\
\text { - Workshop de intercâmbio e aprendizagem na Guatemala. }\end{array}$ \\
\hline $\begin{array}{c}1^{\circ} \text { Semestre de } \\
2013\end{array}$ & $\begin{array}{l}\text { - Reunião para apreciação e aprovação dos indicadores acrianos e seu plano de } \\
\text { monitoramento; } \\
\text { - Construção e lançamento do folder da CEVA; } \\
\text { - Organização e realização do Seminário } 2011-2012 \text { da CEVA; } \\
\text { - Reunião para validação da metodologia e dos fluxos de monitoramento do manual para } \\
\text { monitoramento das salvaguardas do SISA; } \\
\text { - Participação na oficina de apresentação e revisão do manual mencionado; } \\
\text { - Apoio à publicação do Manual de Monitoramento das Salvaguardas Socioambientais de } \\
\text { REDD+ no SISA. }\end{array}$ \\
\hline
\end{tabular}

Fonte: CARE Brasil e IMC (2013). 
Ressalta-se que a publicação da minuta de indicadores acrianos para o respectivo processo de consulta pública foi feita por meio do Ofício $\mathrm{N}^{\circ}$ 18/2011/GAB/IMC, de 27 de julho de 2011, encaminhado às instituições que integram pelo menos um dos três conselhos estaduais do Acre, às organizações que participaram de alguma forma da consulta pública referente à fase de desenho do SISA e aos atores relevantes interessados no tema, de maneira impressa, por email e disponível na Internet, no sítio do Governo do Acre, durante o período oficial da consulta pública em questão, que foi do dia 27 de julho de 2011 até 26 de setembro de 2011. Esta minuta foi denominada proposta preliminar dos indicadores acrianos e foi o produto levado ao público durante a execução do projeto de testes dos padrões sociais e ambientais de REDD+ junto ao Programa ISA Carbono do Acre.

O ofício citado continha o convite para participação nessa consulta, o roteiro básico para tal participação, o formulário para recebimento de contribuições à proposta de indicadores acrianos, informes gerais sobre o SISA e sobre os padrões sociais e ambientais de REDD+ da Iniciativa Internacional, além da minuta dos indicadores em questão. À CEVA, competia aprovar a revisão, os comentários públicos e as recomendações recebidas durante tal processo de consulta.

Destaca-se que, no projeto de institucionalização dos padrões sociais e ambientais de REDD+ no SISA, a publicação prevista é a do manual de monitoramento das salvaguardas sociais e ambientais no SISA e do folder de divulgação da CEVA, sendo que a publicação do relatório de atividades 2011-2012 desta comissão é por conta dela mesma, podendo tal projeto apoiar a elaboração desse relatório com seus recursos.

\section{Discussões}

Neste caso, a análise refere-se à comparação das publicações previstas no processo de implantação das salvaguardas socioambientais do SISA, ou seja, de implantação dos REDD+ SES, com as publicações feitas, priorizando a questão da possibilidade da sociedade acessar informações, que é a base de processos transparentes que fomentam a participação e o efetivo controle social de políticas públicas.

Considerando as dez etapas previstas no guia para implementação dos REDD+ SES nos países, enfatiza-se que a sexta etapa exige a publicação da minuta dos indicadores e a publicação dos indicadores aprovados e validados pelo Comitê Local de Padrões, que, no caso do Acre, é a CEVA. As etapas 8, 9 e 10 exigem a publicação do relatório preliminar de avaliação do desempenho social e ambiental, da revisão do relatório com comentários respondidos por tal comissão e da publicação do relatório final deste desempenho, respectivamente. Observa-se que as sete primeiras etapas foram concluídas no Acre, após a publicação do manual de monitoramento das salvaguardas socioambientais de REDD+ no SISA, o qual inclui o plano de monitoramento dos indicadores acrianos, aprovado e validado pela CEVA. 
Assim, as publicações relativas aos dois projetos de implementação desses padrões na política em questão se resumem ao Ofício $N^{\circ}$ 18/2011/GAB/IMC, que inclui a publicação da minuta dos indicadores acrianos ao manual mencionado, ao folder de divulgação da CEVA e ao relatório de atividades 2011-2012 de tal colegiado.

A publicação dos indicadores aprovados e validados pelo comitê local só foi contemplada com a publicação recente do manual de monitoramento em questão, porque existiram muitas instâncias simultâneas e complementares, entre as quais: processo de consulta pública dos indicadores acrianos; recomendações recebidas nas duas oficinas sobre gênero e REDD + no âmbito da pesquisa ação desenvolvida no Acre; recomendações feitas pelo GT Indígena; recomendações feitas pelo grupo de especialistas; recomendações do secretariado da Iniciativa Internacional e do Comitê Internacional de Padrões; debate existente nas oficinas internacionais de intercâmbio e aprendizagem entre os países que participam da iniciativa ou pretendem participar; e processo de revisão e aprimoramento dos REDD+ SES, sendo lançada a segunda versão desses padrões em setembro de 2012.

Todas as publicações previstas foram realizadas, enfatizando que a publicação do ofício foi feita pelo IMC com o papel da CEVA já citado; a publicação do manual teve o apoio da CEVA, foi elaborado e publicado pelo IMC, pela CARE Brasil e pelo Instituto de Manejo e Certificação Florestal e Agrícola IMAFLORA; a elaboração e a publicação do folder de divulgação foram conduzidas pela CEVA, IMC e CARE Brasil; e o relatório de atividades foi elaborado e publicado pela CEVA, com o apoio destes dois parceiros.

Como comitê local de padrões, a comissão participou das inúmeras discussões e eventos, fez recomendações e aprovou os indicadores acrianos e o seu plano de monitoramento no mês de março de 2013, que foram a base para a construção do manual de monitoramento das salvaguardas socioambientais no SISA, tendo contribuído também na discussão da metodologia deste monitoramento

Enfatiza-se que as publicações e o apoio mencionados foram possíveis devido aos recursos técnicos, humanos e financeiros disponibilizados pelos dois projetos comentados durante o artigo em questão.

Mesmo com o encerramento destes dois projetos, ficam faltando as etapas 8, 9 e 10 para cumprimento e seguimento deste guia de implementação, que, como exposto acima, envolvem mais publicações.

As principais aprendizagens desse processo de exercício da função de Comitê Local de Padrões pela CEVA foram:

- A alta demanda de trabalho das instituições membro em suas rotinas de trabalho e a atuação voluntária destas mesmas dificultaram o desempenho e a participação de tal colegiado como Comitê Local de Padrões;

- A pouca comunicação do Comitê Internacional de Padrões com a CEVA provocou dificuldades no alinhamento necessário durante a revisão e validação dos indicadores acrianos; 
- Existência de alta demanda por programa de fortalecimento e capacitação contínuos para funcionamento da CEVA como Comitê Local de Padrões;

- A necessidade de aprimoramento e de apoio à participação indígena na CEVA;

- O reconhecimento nacional e internacional do Acre como protagonista de uma experiência voltada para Mecanismos de Incentivos a Serviços Ambientais constitui-se como um fato que eleva a responsabilidade da CEVA.

Em relação aos desafios, ressaltam-se:

- O próprio funcionamento da CEVA como Comitê Local de Padrões, por causa da dependência identificada, referente aos recursos dos projetos executados e concluídos;

- A necessidade de garantir a presença contínua dos membros titulares da comissão nas suas reuniões e em outras atividades;

- O Apoio com disponibilização de técnico(a) para dedicação integral às ações e atividades pertinentes à implementação, ao uso e ao monitoramento dos REDD+ SES no SISA, bem como das atividades decorrentes das funções da CEVA como Comitê Local de Padrões;

- A aplicação de programa de fortalecimento e capacitação para apoiar o funcionamento da CEVA como Comitê Local de Padrões diante da situação já levantada;

- O exercício de uma relação mais próxima entre o Coletivo dos Conselhos e a CEVA para acompanhar, deliberar, sugerir e aprender sobre O SISA, aperfeiçoando-o;

- A aproximação do Comitê Internacional de Padrões com o Comitê Local de Padrões (CEVA);

- A participação indígena, iniciando a relação e a comunicação da CEVA com o GT Indígena, visando a possibilidade de participação ativa deste GT neste colegiado.

Tratando-se das oportunidades, frisam-se:

- O acompanhamento e a avaliação do estabelecimento de uma estrutura de governança dos REDD+ SES a longo prazo no SISA;

- A procura pela garantia do cumprimento das salvaguardas sociais e ambientais no SISA, a partir da validação do processo de monitoramento referente ao atendimento dos princípios e critérios previstos nesses padrões, em implementação no Acre;

- O aproveitamento da participação e espaços dos Workshops de Intercâmbio e Aprendizagem da Iniciativa Internacional em busca de fortalecimento e capacitação;

- A possibilidade de continuidade de atividades em cooperações estratégicas.

Enfim, a principal recomendação à CEVA no seu exercício de comitê local de padrões é a constante busca pela capacitação, formação e fortalecimento 
institucional para avaliar e validar o monitoramento das salvaguardas, compreendendo e fazendo uso da ferramenta de tal monitoramento, que é o manual publicado, para que realmente possa sugerir e exigir o aperfeiçoamento dessa política pública, o cumprimento de direitos, a promoção da transparência, da participação e o efetivo controle social, no que tange à validação do monitoramento do desempenho social e ambiental desta política.

Tal recomendação pode ser concretizada ou executada por meio de parcerias e cooperações institucionais para captação, gestão e aplicação de recursos e para apoio ao desenvolvimento das ações e atividades da CEVA como comitê local de padrões até o momento de sua autonomia no desenvolvimento das mesmas.

A recomendação feita justifica-se a partir da perspectiva do controle social ampliado, comentada na fundamentação teórica deste artigo, que é resultado da atuação autônoma e qualificada das organizações da sociedade civil na constituição de um processo de construção coletiva de projetos de sociedade e de propostas de políticas públicas que englobam: transparência e acesso à informação sobre as políticas e ações públicas; monitoramento e possibilidade de acompanhamento sistemático da execução de ações; e participação social na definição e no desenvolvimento das mesmas.

\section{Considerações finais}

É relevante lembrar que a participação social nas diferentes etapas das políticas públicas passa, primeiramente, pelo acesso à informação qualificada e à transparência.

Nesse sentido, percebe-se que o acompanhamento feito sobre o nível de transparência relativa às ações e atividades da CEVA aponta para um bom nível de transparência, pois as publicações previstas foram concretizadas.

Por outro lado, fica evidente a grande dificuldade de tal comissão em garantir a transparência necessária e esperada no SISA, já que as publicações realizadas dependeram diretamente dos recursos dos projetos executados em cooperação de órgão público com organização não governamental.

Essa evidência é fortalecida a partir do fato do colegiado em questão não ter um sítio eletrônico próprio para estabelecer comunicação direta com os atores interessados no tema, ou seja, não existe ferramenta independente para comunicação e divulgação. Além disso, há pequena quantidade de campanhas veiculadas nos meios de comunicação e o sítio eletrônico usado no momento encontra-se desatualizado, precisando de atualização constante. Por enquanto, as informações desse colegiado são disponibilizadas no sítio eletrônico do Governo do Acre.

Enfim, nota-se a dependência direta e grande da comissão mencionada em relação ao poder público na tentativa de garantir a transparência, o que leva a concluir que esse órgão de controle social tem deficiências no que refere-se à 
promoção do acesso às informações e à sua atribuição de buscar a transparência na política pública em pauta.

Para concluir, ressalta-se que o controle social necessita de certa independência das instituições da sociedade civil em relação às organizações que representam o poder público constituído, em busca de posicionamentos imparciais, apesar das cooperações entre os diversos setores da sociedade serem benéficas.

\section{REFERÊNCIAS}

ACRE. Lei $\mathrm{N}^{\circ} 2.308$, de 22 de outubro de 2010, que cria o Sistema Estadual de Incentivos a Serviços Ambientais - SISA, o Programa de Incentivos por Serviços Ambientais - ISA Carbono e demais Programas de Serviços Ambientais e Produtos Ecossistêmicos do Estado do Acre. Diário Oficial do Estado do Acre, de 05 de novembro de 2010.

BONFANTE, T. M.; VOIVODIC, M.; FILHO, L. M. Desenvolvendo Salvaguardas Socioambientais de REDD+: um guia para processos de construção coletiva. Piracicaba, SP: Imaflora, 2010. 40p.

BORN, R. H.; TALOCCHI, S. Proteção do capital social e ecológico: por meio de compensações por serviços ambientais (CSA). São Paulo: Peirópolis; São Lourenço da Serra, SP: Vitae Civilis, 2002. p. 27-46.

CENAMO; M. C. et al. Guia sobre projetos de REDD+ na América Latina. Manaus, Brasil, 2010. 96p.

COMISSÃO ESTADUAL DE VALIDAÇÃO E ACOMPANHAMENTO; INSTITUTO DE MUDANÇAS CLIMÁTICAS E REGULAÇÃO DE SERVIÇOS AMBIENTAIS DO ACRE; CARE BRASIL. Folder de divulgação da CEVA do SISA. Rio Branco, Acre, Brasil, 2013.

COMISSÃO ESTADUAL DE VALIDAÇÃO E ACOMPANHAMENTO. Relatório anual2011-2012. Rio Branco, Acre, Brasil, 2013.

CONTROLADORIA GERAL DA UNIÃO. Secretaria de Prevenção da Corrupção e Informações Estratégicas. Controle Social: orientações aos cidadãos para participação na gestão pública e exercício do controle social. 2. Ed. Brasília, DF, 2010 (Coleção Olho Vivo)

CYMBALISTA, R. et al. Políticas públicas para o centro: controle social do financiamento do BID à Prefeitura Municipal de São Paulo, São Paulo: Instituto Pólis, 2008. 160p.

GTA; CNS; COIAB. Redd saiba mais. Brasília, 2010.

GUEDES, F. B.; SEEHUSEN, S. E. (org.). Pagamentos por serviços ambientais na mata at/ântica: lições aprendidas e desafios. Brasília: MMA, 2011. p. 225-249. 
IMC; CARE BRASIL; IMAFLORA. Manual de monitoramento das salvaguardas socioambientais de REDD+ no SISA. Rio Branco, Acre, Brasil, 2013.

IPAM. Rumo ao REDD+ jurisdicional: pesquisa, análises e recomendações ao Programa de Incentivos aos Serviços ambientais do Acre (ISA Carbono). Brasília, DF, 2012. 53p.

MOSS, N.; NUSSBAUM, R. A review of three REDD+ safeguard initiatives. Forest Carbon Partnership Facility and UN-REDD Programme. 2011. 28p.

PARKER, C. et al. O pequeno livro do REDDt: um guia de propostas governamentais e não-governamentais para a redução de emissões por desmatamento e degradação. Global Canopy Foundation, 2009. 71p.

RANDO, Ayri Saraiva. Salvaguardas socioambientais no SISA: CEVA como comitê local de padrões. In. Seminário de apresentação das ações e resultados da CEVA em 2011 e 2012. Rio Branco, Acre, 2013.

REDD + SES. Diretrizes para o uso dos padrões sociais e ambientais para REDD+ em nível de país. Versão 2, 2012. Disponível em <www.redd-standards.org>. Acesso em: 13 abr. 2015.

REDD+ SES. Social and Environmental Standards. Padrões Sociais e Ambientais para REDD+. Versão 1 de padrões para REDD+, 2010. Disponível em: <www.redd-standards.org >. Acesso em: 27 out. 2012.

REDD+ SES. Social and Environmental Standards. Padrões Sociais e Ambientais para REDD+. Versão 2 de padrões para REDD+, 2012. Disponível em: <www.redd-standards.org >. Acesso em: 19 jan. 2013.

SEMINÁRIO DE APRESENTAÇÃO DAS AÇÕES E RESULTADOS DA CEVA EM 2011 E 2012, 2013, Rio Branco. Documento de sistematização...Projeto institucionalização dos padrões sociais e ambientais de REDD+ no SISA. Rio Branco, Acre: CARE Brasil e IMC, 2013.

SERAFIM, Lizandra. Controle social nas agências reguladoras brasileiras: entre projetos políticos e modelo institucional. A ANEL nos Governos FHC e Lula (19952005). Dissertação (Mestrado em Ciência Política). IFCH - UNICAMP, Campinas, 2007.

WUNDER, S. et al. Pagamentos por serviços ambientais: perspectivas para a Amazônia Legal. Brasília: MMA, 2008. 136p. (Série Estudos, 10). 


\section{Sobre os autores}

Ayri Saraiva Rando

Engenheiro Ambiental, Mestre em Desenvolvimento Regional pela Universidade Federal do Acre UFAC e consultor da SOS Amazônia.

Endereço: Rua 24 de Maio, 104, Segundo Andar, República. 01041000 - São Paulo, SP - Brasil.

E-mail: ayrirando@gmail.com

\section{Marta Nogueira de Azevedo}

Historiadora, Mestre em Desenvolvimento Regional pela Universidade Federal do Acre - UFAC e técnica do Instituto de Mudanças Climáticas e Regulação de Serviços Ambientais do Acre - IMC.

Endereço: R. Benjamin Costant, 856, Centro. 69900-160 - Rio Branco, AC - Brasil.

E-mail: marta.azevedo@ac.gov.br 